\title{
PROTOTIPE TABUNG SEMPROT PUPUK CAIR BERBASIS WAHANA QUADCOPTER BAGI LAHAN TANAMAN PADI
}

\author{
Son Ali Akbar ${ }^{1}$, Anton Yudhana ${ }^{2}$ \\ ${ }^{1,2}$ Jurusan Teknik Elektro, Fakultas Teknologi Industri, Universitas Ahmad Dahlan \\ e-mail : sonali@ee.uad.ac.id ${ }^{1}$,eyudhana@gmail.com²
}

\begin{abstract}
Rice crop fertilization activities generally rely on based traditional of spray equipment. Their methods have used the influence of the traditional farmer on impact rice production. However, the problem facing paddies can touch by the farmer. In this research is providing the latest solutions with the application of modern vehicle technology UAV aircraft based on multirotor type (i.e., quadcopter). By quadcopter, brings appliance contains liquid fertilizer one compost can be spread through the air. The system of mutually connected between spray tube device and vehicle of quadcopter can be controlled the autonomous operate from a home based. The quadcopter can be brought liquid fertilizer to $1000 \mathrm{ml}$ with two sprayers. Also, the research is a comparison of time and become discharge liquid fertilizer of the effectiveness this work on paddies farming.
\end{abstract}

Keywords : Paddy, Tube sprayer, Quadcopter

INTISARI

Kegiatan pemupukan pada tanaman padi umumnya bersifat tradisional dengan mengandalkan alat semprot panggul. Pengaruh metode yang digunakan petani tradisional berdampak pada produksi tanaman padi. Kedala yang dihadapi adalah area persawahan yang tersentuh oleh para petani. Penelitian ini memberikan solusi terbaru dengan penerapan teknologi modern berbasis wahana pesawat UAV jenis multirotor (quadcopter). Wahana ini membawa alat tabung semprot berisi pupuk cair yang dapat menyebarkan pupuk melalui udara tanpa menyentuh area persawahan. Sistem yang saling terintgrasi antara alat tabung semprot dan wahana multirotor (quadcopter) dapat bekerja secara autonomous yang dikontrol dari jarak jauh. Daya angkat multirotor dapat membawa $1000 \mathrm{ml}$ pupuk cari dengan luaran dua buah selang semprot. Perbandingan waktu dan debit cairan pupuk menjadi tolak ukur hasil seberapa efektifitas perangkat ini bekerja pada setiap area lahan persawahan

Kata kunci : Tanaman padi, Tabung semprot, Quadcopter.

I.

\section{PENDAHULUAN}

Mahluk hidup sejatinya membutuhkan asupan untuk hidup. Asupan yang selama ini menjadi bahan pokok salah satunya berupa tanaman padi. Pada prakteknya dalam mengelola tanaman padi dibutuhkan sumber daya alam dan sumber daya manusia yang mencukupi. Ditelisik kondisi saat ini, sumber daya manusia dalam bercocok tanam masih menggunakan cara tradisional terutama saat proses penyebaran pupuk sehingga akan berdampak dari hasil kualitas tanaman padi.

Melihat studi kelayakan proses bercocok tanam tanaman padi perlunya kontribusi lain untuk meningkatkan kualitas yang diperoleh. Dengan kemajuan teknologi terbaharukan yang telah banyak diterapkan diberbagai bidang menjadi tolak ukur kontribusi yang diberikan oleh teknologi modern. Salah satu dari penerapan teknologi modern adalah teknologi pesawat tanpa awak (UAV) yang saat ini banyak dikembangkan dan berpontensi menunjang banyak bidang aspek [1][2]. Diketahui, dibeberapa bidang agrikultur juga ada yang telah menerapkan teknologi sebagai alat bantu, sepertinya menggunakan teknologi pesawat tanpa awak atau disebut UAV [3][4].

Dari studi kasus tersebut menjadi latar belakang penelitian ini menerapakan teknologi UAV untuk menunjang kualitas saat becocok tanam tanaman padi. Pesawat UAV yang diperbantukan sebagai media dalam proses penyebaran pupuk melalui perangkat bantu tabung semprot yang terintegrasi secara autonomous. Penerapan UAV pada penelitian ini berusaha untuk mengestimasi kelemahan meningkatkan kualitas pada cara tradisional 
menjadi strategis dalam hasil bercocok tanam tanaman padi.

II.

\section{METODOLOGI}

\section{A. Rancang Desain Quadcopter}

Pesawat UAV tipe VTOL yang digunakan pada penelitian ini jenis quadcopter. Pada quadcopter dipasang sebuah tabung semprot bervolume $1000 \mathrm{ml}$ dengan selang semprot yang menjadi luaranya pupuk cair. Metode yang digunakan adalah rute pilot otomatis dan aktivasisis temperangkat berbasis telemetri. Pada Gambar 1 menunjukkan bentuk quadcopter yang digunakan penelitian. Rancang desain quadcopter yang dibangun memiliki perbandingan $(1: 0,5)$ antara berat pesawat dengan daya angkat beban yang dapat terpasang.

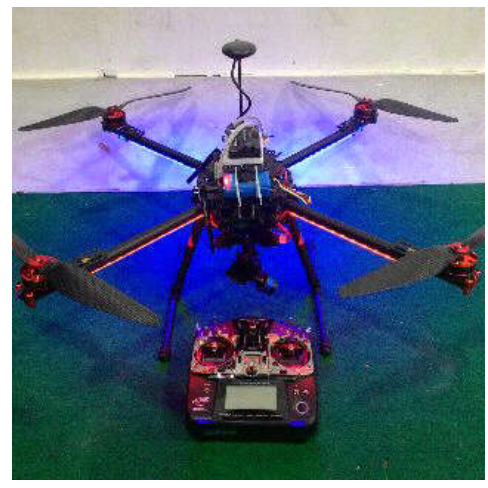

Gambar 1. Quadcopter

Pada sistema quadcopter terpasang perangkat keras tipe APM arduflyer yang digunakan untuk mengontrol sistema pesawat. Perangkat keras APM arduflyer dapat diatur kinerjanya melalui perangkatlunak yang ditunjukan pada Gambar 2.

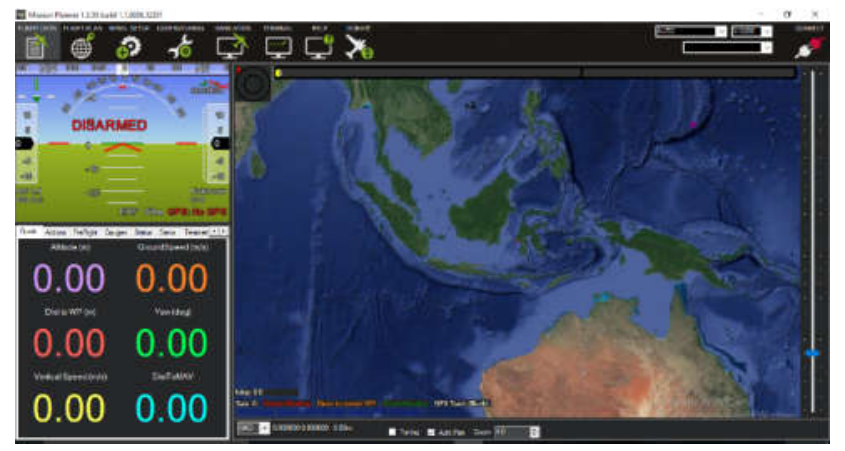

Gambar 2. Perangkat Lunak Mission Planner [5]

Mission Planner merupakan visual sistem kontrol navigasi untuk mengetahui indikator kinerja quadcopter yang digunakan dari jarak jauh menggunakan perangkat telemetri dengan metode komunikasi half-duplex.

\section{B. Rancang Bangun Tabung Semprot}

Tabung semprot yang digunakan berfungsi untuk menyiramkan pupuk cair kepada tanaman padi melalui selang semprot.Tabung semprot didesain secara otomatis untuk menyemprot pupuk yang terintegrasi dengan sistema quadcopter saat diaktifkan melalui remote jarak jauh.Volume tabung semprot dapat menampung $1000 \mathrm{ml}$ pupuk cair.

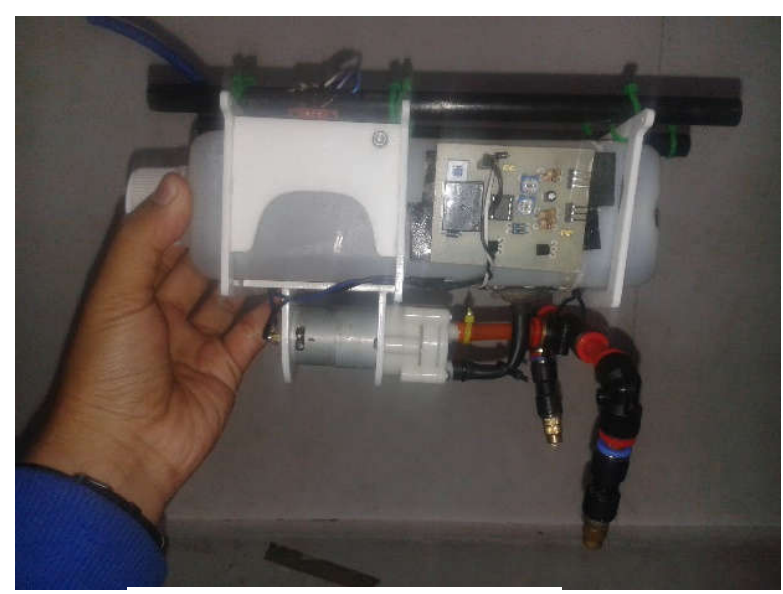

Gambar 3. Tabung semprot

Pada Gambar 3 ditunjukkan desain perangkat tabung semprot yang telah dipasang perangkat keras elektronis untuk mengatur kinerja perangkat. Beberapa perangkat keras yang digunakan Mikrokontroler, Motor DC waterpump dan driver motor dan selang semprot berdiameter $6 \mathrm{~mm}$.

Perangkat keras tabung semprot diatur melalui perangkat lunak pemograman dengan basis bahasa $\mathrm{C}++$ pemograman. Tabung semprot dipasang pada quadcopter pada bagian bawah badan pesawat yang ditunjukan pada Gambar 4 .

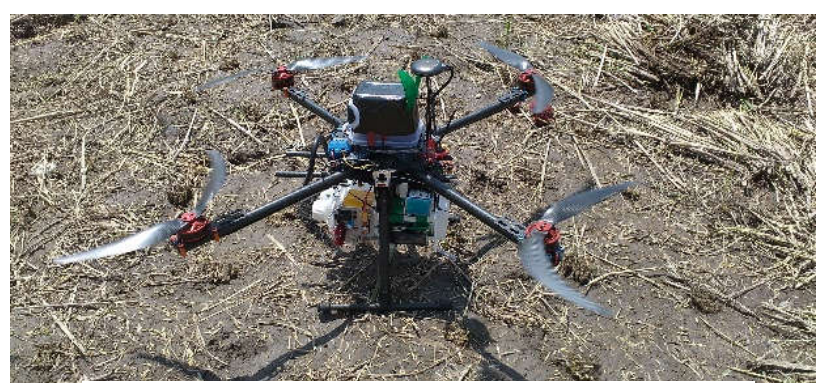

Gambar 4. Tabung semprot terpasang pada quadcopter 
Cara kerja antara sistema quadcopter dan perangkat tabung semprot ditunjukkan pada Gambar 5.

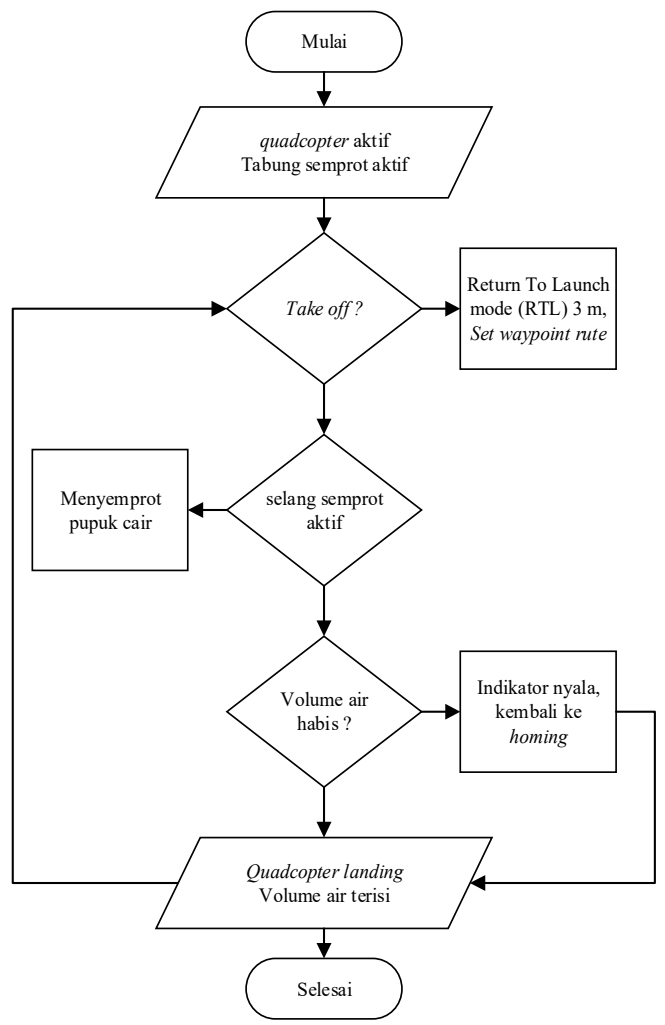

Gambar 5. Diagram alir seluruh sistem

Diagram alir sistem menjelaskan secara aktual proses kinerja 2 sistem perangkat yang terintegrasi ketika proses alat bekerja.

\section{Perangkat Keras}

Penelitian ini, pada perangkat tabung semprot menggunakan beberapa komponen elektronis yang dirancang secara otomatis dan dapat bekerja secara otomatis sebagai berikut:

1. Mikrokontroler

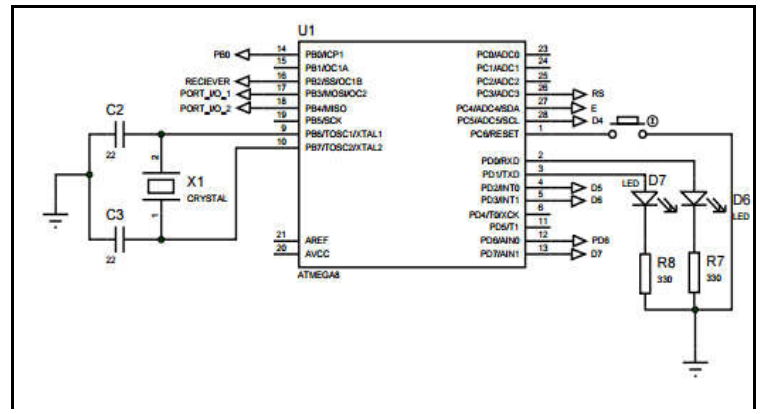

Gambar 6. Skematik mikrokontroller ATmega8

Tipe chip mikrokontroler ATmega8 produk AVR Atmel dengan kemampuan mengolah data 8 bit dan dapat bekerja dengan tegangan 4,5 -
5,5 Volt. Mikrokontroler ini termasuk kategori rendah pembiayaan dan berkemampuan tinggi.

\section{Driver motor}

Perangkat motor membutuhkan perangkat keras bantu driver yang berfungsi mengontrol daya dan pergerakan motor secara teratur.

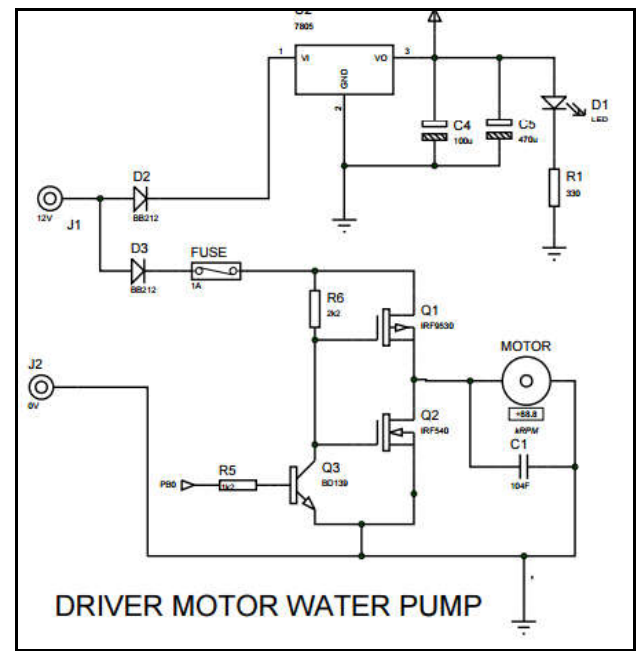

Gambar 7. Skematik driver motor

Rangkaian driver motor menggunakan relay dan swith motor dibantu dengan rangkaian komparator op-amp tipe LM328 sebagai penguat sinyal pengaturan PWM driver motor terhadap komunikasi data pada telemetri ardupilot.

\section{Perhitungan Matematika}

Penelitian ini menggunakan rumus matematika untuk mengetahui batasan kemampuan perangkat dalam beroperasi secara kuantitas. Tujuan perhitungan untuk menentukan perbandingan kualitas pengujian yang dilakukan berulangkali secara signifikan dan adanya perbedaan yang dapat diketahui melalui data statistik. Rumusan matematis yang digunakan yakni mengetahui rerata dan simpangan baku.

$$
\bar{x}=\frac{\sum_{i}^{x}=1^{x i}}{n}
$$

Rumus di atas untuk mencari nilai rerata, dimana $x_{i}=$ data ke $\mathrm{i}$, dan $\mathrm{n}=$ jumlah sampel. Hasil nilai rerata keseluruhan untuk mengukur estimasi waktu yang dibutuhkan pada pengujian perangkat yang dilakukan. Selain itu untuk mengetahui nilai statistik simpangan baku dirumuskan sebagai berikut : 


$$
s=\sqrt{\frac{\sum_{i=1}^{n}\left(x_{i}-\bar{x}\right)^{2}}{n-1}}
$$

dimana $\bar{x}=$ nilai rerata, Kemudian, nilai debit air yang menjadi tolak ukur seberapa banyakpupuk cari dapat tersebar dalam satu area.

$$
D=\frac{v}{t}
$$

dimana $\mathrm{D}=$ debit (liter/detik), $\mathrm{v}=$ volume air (liter), $\mathrm{t}=$ waktu (detik)

III.

\section{HASIL DAN PEMBAHASAN}

Hasil pengujian telah dilakukan uji terbang dan penyebaran pupuk cair pada kawasan pertanian didaerah Sleman DIY dengan luasan area $20 \times 6 \mathrm{~m}^{2}$.

Pembahasan pada makalah penelitian ini meliputi beberapa pengujian yang dilakukan untuk mengetahui kemampuan alat bekerja dibeberapa kondisi yang berbeda sebagai berikut :

1. Pengujian menggunakan dua kondisi jumlah luaran selang semprot

2. Pengujian menggunakan dua kondisi penyebaran (stabil dan tidak stabil) saat penerbangan

3. Pengujian menggunakan dua kondisi volume tabung semprot $(1000 \mathrm{ml}$ dan 500 $\mathrm{ml})$

4. Pengujian mengetahui estimasi waktu, dan debit cairan saat proses penyebaran

\section{A. Pengujian Satu Selang Semprot}

Pada pegujian pertama digunakan satu buah luaran dari selang semprot pada tabung semprot untuk mengetahui kemampuan alat tabung semprot menggunakan satu luaran selang semprot. Pada Gambar 8 dan Gambar 9 menunjukkan hasil pengujian yang berskala grafik.

Tabel 1. Nilai statistik volume pupuk cair $1000 \mathrm{ml}$

\begin{tabular}{|c|c|c|c|}
\hline Kondisi & $\begin{array}{c}\text { Rerata } \\
\text { (detik) }\end{array}$ & $\begin{array}{c}\text { Simpangan } \\
\text { baku } \\
\text { (detik) }\end{array}$ & $\begin{array}{c}\text { Debit air } \\
\text { (liter/detik) }\end{array}$ \\
\hline Stabil & 8.14 & 0.46 & 122.95 \\
\hline Tidakstabil & 7.83 & 0.45 & 127.67 \\
\hline
\end{tabular}

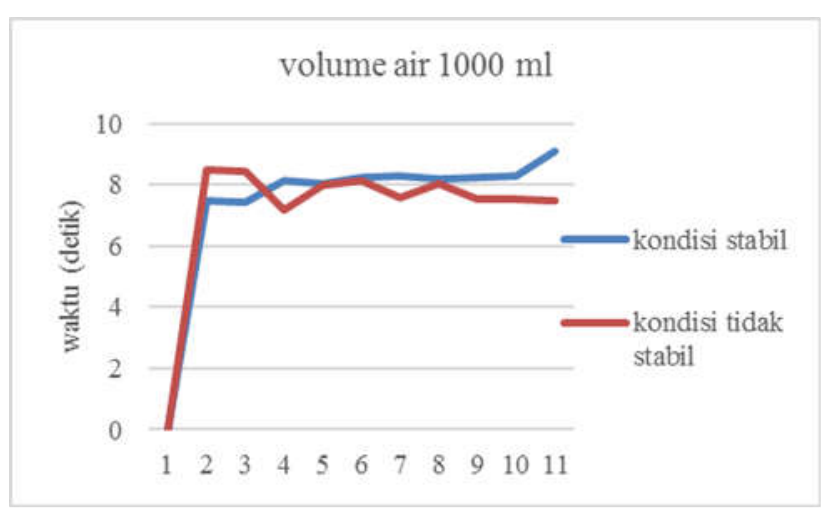

Gambar 8. Grafik penyebaran pupuk bervolume $1000 \mathrm{ml}$

Tabel 2. Nilai statistik volume pupuk cair $500 \mathrm{ml}$

\begin{tabular}{|c|c|c|c|}
\hline Kondisi & $\begin{array}{c}\text { Rerata } \\
\text { (detik) }\end{array}$ & $\begin{array}{c}\text { Simpangan } \\
\text { baku } \\
\text { (detik) }\end{array}$ & $\begin{array}{c}\text { Debit air } \\
\text { (liter/detik) }\end{array}$ \\
\hline Stabil & 3.43 & 0.24 & 145.94 \\
\hline Tidakstabil & 3.19 & 0.28 & 156.99 \\
\hline
\end{tabular}

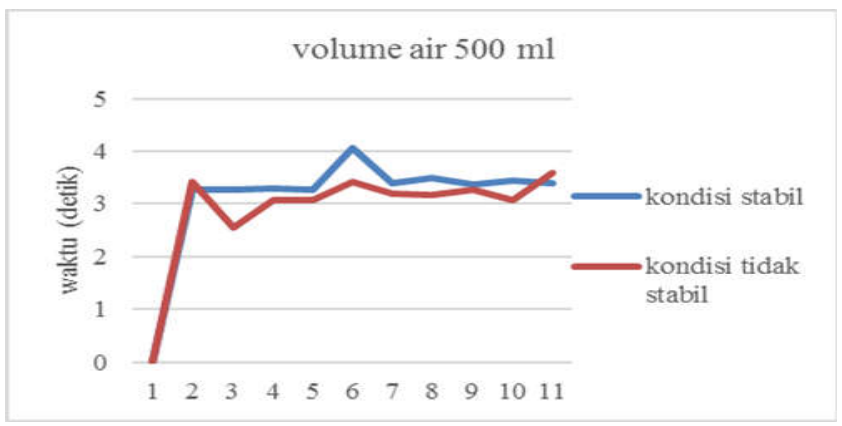

Gambar 9. Grafik penyebaran pupuk bervolume 500 $\mathrm{ml}$

\section{B. Pengujian Dua Selang Semprot}

Pada pegujian pertama digunakan dua buah luaran dari selang semprot pada tabung semprot untuk mengetahui kemampuan alat tabung semprot menggunakan satu luaran selang semprot. Pada Gambar 10 dan Gambar 11 menunjukkan hasil pengujian yang berskala grafik.

Tabel 3. Nilai statistik volume pupuk cair $1000 \mathrm{ml}$

\begin{tabular}{|l|c|c|c|}
\hline Kondisi & $\begin{array}{c}\text { Rerata } \\
\text { (detik) }\end{array}$ & $\begin{array}{c}\text { Simpangan } \\
\text { baku } \\
\text { (detik) }\end{array}$ & $\begin{array}{c}\text { Debit air } \\
\text { (liter/detik) }\end{array}$ \\
\hline Stabil & 1.35 & 0.08 & 741.84 \\
\hline Tidakstabil & 1.43 & 0.04 & 701.26 \\
\hline
\end{tabular}




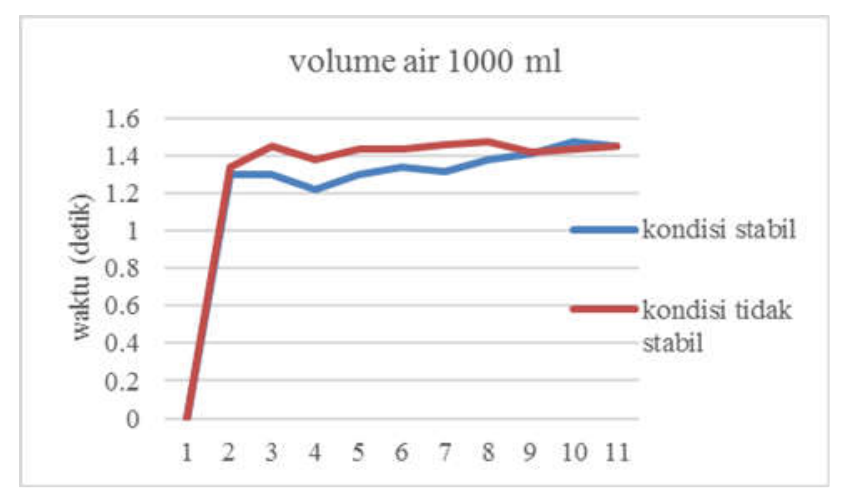

Gambar 10. Grafik penyebaran pupuk bervolume $1000 \mathrm{ml}$

Tabel 4. Nilai statistik volume pupuk cair $500 \mathrm{ml}$

\begin{tabular}{|l|c|c|c|}
\hline Kondisi & $\begin{array}{c}\text { Rerata } \\
\text { (detik) }\end{array}$ & $\begin{array}{c}\text { Simpangan } \\
\text { baku } \\
\text { (detik) }\end{array}$ & $\begin{array}{c}\text { Debit air } \\
\text { (liter/detik) }\end{array}$ \\
\hline Stabil & 0.50 & 0.02 & 1006.04 \\
\hline Tidakstabil & 0.66 & 0.18 & 758.73 \\
\hline
\end{tabular}

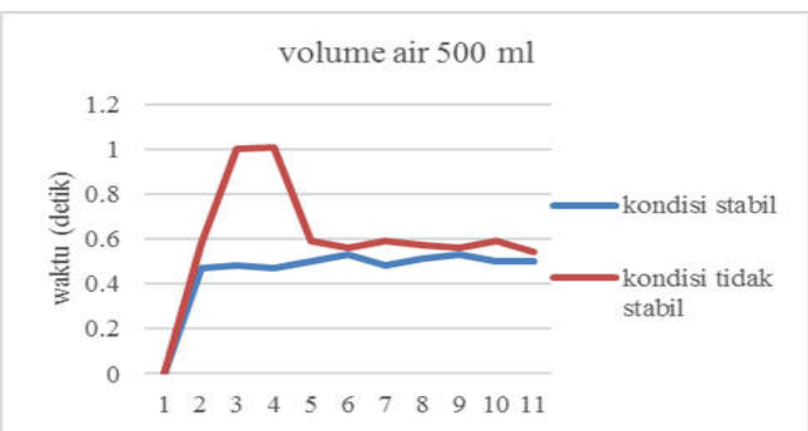

Gambar 11. Grafik penyebaran pupuk bervolume $500 \mathrm{ml}$

\section{KESIMPULAN}

Dari hasil beberapa pengujian yang dilakukan pada penelitian ini diperoleh dapat dianalisis perbandingan dari setiap uji kemampuan alat pada kondisi yang berbedabeda. Pada dua pengujian luaran dari selang semprot yang dihasilkan menunjukkan bahwa dengan menggunakan dua buah selang semprot, estimasi waktu dan jumlah debit cairan pada proses penyebaran pupuk berbanding lebih cepat dan lebih banyak dari pada dengan pengujian menggunakan luaran satu buah selang semprot. Pengujian yang dilakukan dengan dua kondisi penerbangan yakni stabil dan tidak stabil (goncangan) juga menunjukkan luaran berbeda yang disebabkan pengaruh faktor alam seperti halnya kondisi angin yang tidak beraturan. Penelitian selanjutnya akan melakukan pengujian dengan menambah volume alat tabung semprot dan jumlah luaran selang semprot.

\section{REFERENSI}

[1] N. S. Widodo, A. Yudhana, and Sunardi, "Low Cost Open Source based UAV for Aerial Photography," Int. J. Innov. Res. Adv. Eng., vol. 1, no. 10, pp. 416-424, 2014.

[2] P. Tripicchio, M. Satler, G. Dabisias, E. Ruffaldi, and C. A. Avizzano, "Towards Smart Farming and Sustainable Agriculture with Drones," 2015 Int. Conf. Intell. Environ., pp. 140-143, 2015.

[3] A. A. Saputra and A. Dharmawan, "Rancang Bangun Quadcopter untuk Pemantauan Kadar Karbon Monoksida di Udara," vol. 3, no. 1, pp. 11-22, 2013.

[4] N. M. Sari and D. Kushardono, "Klasifikasi Penutup Lahan Berbasis Obyek Pada Data Foto Uav Untuk Mendukung Penyediaan Informasi Penginderaan Jauh Skala Rinci (Object Based Classification Of Land Cover On Uav Photo Data To Support The Provision Of Detailed-Scale Remote Sensing Informati," vol. 11, no. 2, pp. 114-127, 2014.

[5] A. D. Team, "Mission Planner Overview," 2016. [Online]. Available: http://ardupilot.org/planner/docs/missionplanner-overview.html. 